\title{
0 Princeps Otávio Augusto na Biografia Antiga: um estudo de caso sobre Nicolau de Damasco e Suetônio
}

\author{
The Princeps Octavian Augustus in the Ancient Biography: a case study \\ based on Nicolau of Damascus and Suetonius
}

Carlos Eduardo da Costa Campos* Universidade Federal de Mato Grosso do Sul (UFMS), Campo Grande, MS, Brasil

\begin{abstract}
RESUMO: A proposta do artigo é problematizar as representações sobre Otávio Augusto em Nicolau de Damasco e Suetônio com o intuito de compreender os traços biográficos augustano nas duas obras. A documentação é relevante para a reflexão, pois consiste em temporalidades de períodos distintos. Desse modo, o artigo estabelece processos de análise comparativos entre as duas escritas biográficas e leva em consideração o contexto histórico de cada um dos autores. Nosso argumento é o de que o saber biográfico de ambos tendeu a uma valoração de Augusto como bom governante e um articulador das instituiçóes que estavam sujeitas aos controles sociais dele e de seu grupo naquele período.
\end{abstract}

PALAVRAS-CHAVE: Biografia Antiga. Otávio Augusto. Principado.

\begin{abstract}
The purpose of this paper is to problematize the representations about Octavian Augustus in Nicolaus of Damascus and Suetonius to understand the Augustan biographical features in the two works. The documentation is relevant to the reflection, since it consists of temporalities of different periods. Thus the paper establishes a comparative analysis between the two biographical writings and takes into account the historical context of each of the authors. Our argument is that the biographical knowledge of both tended to a valuation of Augustus as a good ruler and an articulator of the institutions that were subject to his and her group's social controls in that period.
\end{abstract}

KEYWORDS: Ancient Biography. Octavian Augustus. Principate.

\footnotetext{
*Professor Adjunto da Universidade Federal de Mato Grosso do Sul, Centro de Ciências Humanas e Sociais (CCHS-UFMS). Doutor em História pela Universidade Estadual do Rio de Janeiro (UERJ).

E-mail: eduygniz@hotmail.com. Orcid: https://orcid.org/0000-0002-9845-5980.
} 
A Literatura Antiga é um elemento fundamental para as pesquisas em História Antiga. Entretanto, apesar da quantidade expressiva de trabalhos feitos nas Instituições de Ensino Superior envolverem obras literárias e autores antigos, também se identifica certa escassez de reflexôes sobre as suas especificidades. É vital problematizarmos: o que é a Literatura na Antiguidade? Qual a sua função social? Quais as características dos gêneros literários que retrataram o princeps Augusto? Tais questões não são dadas naturais, assim necessitando de maiores análises. Afinal, a preocupação com a forma e o conteúdo dos discursos pode proporcionar visões diferentes de uma mera catalogação e manipulação de informações, pois leva ao conhecimento do contexto de produção dos autores antigos, tanto gregos quanto romanos.

Quando abordamos a Literatura Antiga, notamos que as vertentes filológicas mais atuais consideram quaisquer textos transmitidos pela tradição dos manuscritos, bem como produtos da Antiguidade, o que engloba o próprio controverso período de Antiguidade Tardia. Temos em mente que estamos diante de uma vasta produção que vai da Ilíada à Odisseia, no século VIII AEC, até a Antiguidade Tardia, com Amiano Marcelino no século IV EC, como foi salientado por Anderson Martins Araújo Esteves (2015, p. 200-210). Dessa maneira, percebemos que a definição de texto literário se torna flexível. Afinal, ela abarca desde os poemas épicos, até mesmo as tragédias e as comédias, bem como a poesia lírica e a prosa.

Complementamos a visão acima com Michael von Albrecht (1997, p. 1-2), pois este frisa que, desde o início, devemos fazer uma distinção entre as ideias antigas e as modernas de literatura. Afinal, em adição à poesia e aos romances, a Literatura Antiga incluía gêneros que, para os leitores atuais, não são associados diretamente como literatura: a oratória, a história, os escritos filosóficos, isto é, a prosa formal no sentido mais lato. Devemos também considerar até mesmo os trabalhos de cunho técnico que tratavam da agricultura, de arquitetura, do direito, da guerra, assim como os livros de magia, as biografias, os comentários e a própria epistolografia como atividades literárias na Antiguidade, visão essa que se aproxima com a de Anderson Martins Esteves.

Verificamos que se as fronteiras atuais entre a História e a Literatura são bem delimitadas, para a Antiguidade a produção literária detinha outras especificidades que a tornam, no momento, a principal base para as nossas pesquisas. Existem boas razóes para que a literatura detenha a centralidade para a prática de História Antiga. Afinal, tais textos fornecem um enorme volume de evidências antigas, pois, como percebemos, uma produção é inesgotável para o pesquisador, visto que tudo depende das questóes e olhares que se colocam sobre o objeto. Muitos desses materiais literários em idiomas originais podem ser lidos, praticamente, em ediçôes completas com boa qualidade, além do acesso para a pesquisa eletrônica. Soma-se à acessibilidade de traduçóes, os comentários e outros meios interpretativos disponíveis pela internet. Dataçóes e os contextos sociais, muitas vezes, podem ser determinados com precisão relativa (WHITMARSH, 2009, p. 77-86).

Todavia, convergimos com John Marincola (2007, p. 1-10) sobre os rigores metodológicos que o pesquisador contemporâneo deve deter ao abordar uma documentação tão ampla e diversa temporalmente, como a literatura antiga, em suas pesquisas. Dessa forma, os escritos literários que sobreviveram da Antiguidade também devem ser refletidos no que tange às representaçóes que contêm sobre tal época, pois não correspondem à sociedade em sua plenitude. Essas visões são inerentes a alguns grupos ou sujeitos que integravam um segmento social em particular. Apontamos que a Literatura Antiga, nosso objeto de reflexão, contém uma vasta gama de discursos e representações sobre o comportamento de diversos atores políticos, os quais permearam a memória social ${ }^{1}$ de Roma. 
Os pontos supracitados ligam-se também ao gênero e ao estilo literário de uma época. $O$ gênero influenciava o modo de escrita dos autores antigos. Para Esteves (2015, p. 200-210), esse conceito é de alta relevância nas pesquisas em História Antiga: "[...] à medida que, sem prejuízo das características individuais de cada autor, a obra literária antiga é fortemente atrelada aos requisitos de forma e de conteúdo de gêneros pré-existentes”. Sendo assim, um historiógrafo ao dispor-se a produzir sobre a história de Roma, já estava submetido a um conjunto de condicionantes, os quais eram exigências do gênero que ele iria abordar, bem como tecia determinados assuntos em detrimento a outros, da mesma forma que lhe era imposta a prosa como a forma padrão para a escrita desse trabalho. Esteves, Martin e Gaillard convergem que o gênero é um elemento universal, o qual é definido pelo espaço que ocupa na sociedade, à medida que as formas são as maneiras pelas quais os diferentes gêneros se manifestam em cada sociedade (ESTEVES, 2015, p. 200-210; MARTIN, GAILLARD, 1990, p. 10-13). Com isso, percebemos que o gênero é diacrônico, enquanto o estilo é um elemento sincrônico, assim, relacionando-se com um determinado período histórico. Logo, refletir a sincronia não é o simples ato de estabelecer correlaçôes com a produção e ao período histórico em que ela foi gerada. Apesar de ser um conhecimento fundamentado no contexto histórico, questão esta que é indispensável, a mesma não possibilita explicar as convergências de traços da literatura augustana, por exemplo. Por isso, os estilos das obras devem ser analisados como partes de um sistema de pensamento, o qual, apesar de vinculado à ordem social, também é distinto dela e possui autonomia. Assim, Esteves sugere pensarmos a partir do conceito de "época”, que possui características no sentido literário.

Ao tomarmos Esteves (2015) como nossa base, podemos dividir a Literatura Latina por épocas, as quais se relacionam com a História Política de Roma: como Literatura da República, Literatura Augustana e Literatura Imperial. Em nosso trabalho, empregamos a Literatura Augustuna e Imperial, pelas múltiplas evidências sobre Otávio Augusto, nos textos gregos e latinos. Logo, as práticas e associações político-religiosas romanas em relação à legitimidade do referido princeps, contidas nesse vasto corpora documental, é o que nos intriga para investigação, aqui, por meio da biografia e da historiografia antiga.

\section{Biografias sobre o Princeps}

A biografia como um campo de escrita existia em Roma desde o século II AEC, de acordo com José Luís Lopes Brandão (2009, p. 17). Entretanto, é possível perceber “experimentos biográficos” mais recuados com base nas canções de banquetes - como a carmina conuiualia - que possivelmente existiram até ao tempo de Catão, o velho (III AEC). Tal cântico celebrava as virtudes dos heróis que haviam perecido, como foi exposto por Marco Túlio Cícero (Tusculana IV, 2) ${ }^{2}$. Com o passar do tempo, outros “experimentos biográficos” tornaram-se possíveis de ser percebidos em Roma, como nas cerimônias fúnebres da aristocracia, mediante a realização das laudationes. Tal prática foi capaz de reunir alguns elementos basilares da biografia, ao evocar os antepassados, os descendentes, as honras e a aparência física do morto (MADELÉNAT, 1984, p. 39).

O desenvolvimento da escrita biográfica latina adquire novos contornos a partir do século I AEC, período este também denominado de República Romana Tardia. O referido contexto é marcado pela concentração de poder entre os grandes generais romanos, o que colocava as antigas instituições republicanas em posição de fragilidade frente ao poderio militar destes comandantes ${ }^{3}$. 
Diversas foram as modificaçóes políticas e sociais vivenciadas por Roma no período, que culminou com a formulação do Principado de Otávio Augusto. Nesse bojo, verificamos que a biografia latina veio a se desenvolver pelo viés literário, assim como assumiu uma face de propaganda dos aristocratas em meio à disputa pelo acesso ao poder. Um exemplo do que passou a ser comum entre os aristocratas romanos foram os comentários (Commentarii). Segundo Brandão (2009, p. 22), tais práticas de enaltecimento eram escritas pelos magistrados, generais e, posteriormente, pelos principes. Dessa maneira, sendo comum entre a República e o Alto Império. Por intermédio de Arnaldo Momigliano (1993, p. 14), percebemos que as escritas biográficas sobre um determinado personagem apresentavam como principais emissores e promotores os familiares, os libertos e os clientes do biografado. Assim, eles descreviam os feitos e glórias de um protetor ou amigo da família, de forma pública, com isso reforçando os laços sociais.

As primeiras obras biográficas de cunho literário que podem ser evidenciadas são as de Varrão (116-27 AEC) e Cornélio Nepos (100-27 AEC). Os conteúdos versavam sobre pensadores e homens da política, helênicos e latinos, com ênfase nos aspectos particulares dos costumes dos dois povos. As obras de Varrão, as Imagines ou Hebdomades, não chegaram até os dias atuais, mas se sabe que elas englobavam sete retratos de personagens ilustres - desde reis a dançarinos, entre outros - que precediam epigramas que descreviam o personagem, como foi apontado por Arnaldo Momigliano (1993, p. 96). Cornélio Nepos seguiu o caminho de Varrão, assim compondo obras que confrontam os costumes de romanos e helenos, com os de outros povos como cartagineses e persas. É interessante demarcar a sua nítida distinção entre História e Biografia, a qual se faz presente em sua obra (Vidas, Prefácio, 1). Desse modo, ele se vale da biografia como um mecanismo que possibilita conhecer os feitos dos grandes homens e, com isso, gerar uma moralização e exemplos de bons cidadãos. Tal modelo de escrita biográfica veio a inspirar autores posteriores, como Plutarco e Suetônio, na visão de Brandão (2009, p. 23).

O cenário cultural romano do século I AEC ao II EC instiga-nos pela intensa atividade literária referente às figuras públicas de Roma, que buscavam projetar as suas reputações divulgando o seu estilo, a sua erudição e as suas realizações. Nesse período de transição, transformações e algumas acomodações políticas entre os personagens públicos romanos, chama-nos a atenção o princeps Otávio Augusto (27 AEC-14 EC). Selecionamos o referido magistrado por sua proeminência política e cultural para Roma e o Mediterrâneo Antigo, assim como a sua perenidade no imaginário social do Ocidente.

Notamos que, a partir do Principado 4 de Augusto, acentuou-se nos trabalhos dos biógrafos latinos e os de matriz cultural helênica o elogio às figuras dos grandes políticos, com ênfase na representação $0^{5}$ dos principes romanos. Brandão (2009, p. 24) frisa que essa forma de produção biográfica foi o viés "[...] mais indicado para historiar o governo de Roma imperial, em que havia concentração das instituiçôes do Estado na pessoa do imperador: pelo que [...] - as virtudes e os vícios - se refletem na condução da história”. Assim, compreendemos a biografia 6 , no período do principado romano, como um conjunto de relatos sobre personalidades ilustres, as quais permearam a memória social de Roma. Ademais, ressaltamos que as fronteiras entre a vida pública e privada, no Mundo Antigo, são tênues e esses cidadãos de destaque, como Augusto, eram intensamente expostos em suas respectivas comunidades tanto em formas de exaltação como também de críticas sociais. Tal fato gerava inúmeros materiais para os escritos biográficos e historiográficos, por exemplo. No caso da biografia, elas apresentavam o estilo de vida que determinado personagem histórico deteve, com 
isso euforizando ${ }^{7}$ ou disforizando ${ }^{8}$ o caráter do sujeito, os seus feitos e conquistas. Contudo, essa construção biográfica poderia variar em aspectos de forma, estilo e até mesmo de conteúdo, pois não podemos esquecer das intencionalidades relativas a cada biógrafo.

Seguindo a perspectiva acima, vemos a biografia como um dos variados instrumentos culturais existentes. Com isso, as geraçóes posteriores passaram a ter a possiblidade de conhecer certos homens que, por seus feitos e glórias, foram selecionados pelos segmentos dirigentes para uma imortalização no horizonte mental romano. Com esse ato de preservação da trajetória pública de um sujeito, evitava-se o seu silenciamento e/ou esquecimento diante do tempo, um fato que driblava vitoriosamente a própria ação da morte física e social' ${ }^{9}$. Logo, temos como perspectiva que a produção biográfica em Roma fornecia um conjunto de exempla, pois ela produzia um efeito pedagógico ensinando aos cidadãos os modelos de comportamento esperados pela sociedade de um princeps, bem como daqueles que assumiam funções na magistratura local e na administração imperial ${ }^{10}$. Endossando nossa assertiva, recorremos a Plutarco que, por conseguinte, buscava expor os vícios e as virtudes de determinados homens e assim pretendia que os seus interlocutores agissem em conformidade aos ensinamentos políticos, sociais e militares, os quais eram transmitidos para a sociedade (PLUTARCO, Vida de Alexandre, 1.2) ${ }^{11}$. Em nosso corpora documental selecionamos os excertos de Nicolau de Damasco e Caio Suetônio Tranquilo.

\section{A produção biográfica de Nicolau de Damasco}

Nicolau de Damasco foi um escritor contemporâneo de Otávio Augusto, em Roma, e de Herodes, na Judéia. Notamos também que ele estivera inserido nas redes do referido "princeps romano e do rei dos judeus" ${ }^{12}$. Nicolau pertencia ao seio aristocrático das principais famílias de Damasco, na província romana da Síria. O pai de Nicolau era Antípatro de Damasco e sua mãe Estratonice, ambos reconhecidos em Damasco por suas virtudes e proeminência social. Segundo o Léxico Bizantino (Suda), Antípatro envolvia-se em missões diplomáticas e julgamentos na cidade de Damasco, assim acumulando cargos centrais na magistratura local (Suda, A' 2705). Dessa forma, percebemos as redes sociais, com as quais Nicolau já circulava em seu processo de formação. Em razão de sua formação aristocrática, o escritor de Damasco tornou-se proficiente em muitas áreas do conhecimento erudito, o que ocorreu também com o aprendizado de determinadas línguas e a literatura, como apresenta em seus escritos sobre si (FGrH 90 F. 131). Como vemos no Léxico Bizantino: "ele foi notável em sua pátria e se destacou entre os seus pares; ele estudou gramática melhor do que ninguém, e, por causa disso, toda a arte da poesia, e ele mesmo escreveu tragédias e comédias famosas" (Suda, N’393).

Clayton Morris Hall (1923, p. 1-2) pontua que a proeminência política e social de Nicolau de Damasco o levou a fazer parte da corte do rei Herodes da Judeia, bem como, posteriormente, a prestar serviços para Arquelao (Arquelaus), o filho e sucessor herdeiro do antigo monarca. Sendo assim, o autor de Damasco passou a função de conselheiro e instrutor, como foi descrito por Plutarco (Simpótica, 8.4) e pelo próprio Nicolau de Damasco em sua autobiografia (FGrH 90 F. 135). É nesse contexto que emerge a História de Herodes, que foi incluída em suas Histórias, uma coletânea em forma de história universal com 144 livros. Para Aryeh Kasher, devido ao conhecimento de Nicolau e sua habilidade com a escrita, Herodes o elevou à categoria de historiógrafo real. Foi por intermédio das redes sociais de Herodes ${ }^{13}$ que Nicolau veio a conhecer o próprio princeps Otávio Augusto, a partir de uma viagem que ambos fizeram para Roma. Com isso, notamos em 
sua autobiografia que Nicolau assumiu o papel de mediador entre os interesses e os problemas que emergiam na província da Judeia e em Roma. Um dos pontos altos dessa função foi quando Nicolau atuou em prol de Arquelao sucessor de Herodes, ao trono, contra Antípatro filho de Herodes e conspirador. A situação foi resolvida com o apoio de César Augusto, para Arquelao (FGrH 90 F. 136).

Com base nos registros de Jane Bellemore (1984), verificamos que as relações sociais desenvolvidas entre Augusto e Nicolau de Damasco se acentuaram na década de 20 AEC. Para a autora, Nicolau tornou-se o tutor de Hélios e Selene, os filhos de Marco Antônio e Cleópatra VII, que foram criados por Otávia, irmã do princeps. Com a referida inserção social, ele passou a circular no ambiente privado da domus ${ }^{14}$ augustana. $\mathrm{O}$ ápice dessa relação social culminou com honrarias concedidas por César Augusto a Nicolau de Damasco, como o próprio relatou em seus escritos (FGrH 90 F. 136).

Para Clayton Hall, Nicolau teve acesso a um material privilegiado ao construir a sua biografia sobre Augusto. Afinal, eles passaram a integrar uma mesma rede social, ao ponto de César tornarse o seu patrono. Apesar de haver pontos que podem ser considerados como tendenciosos pelos vínculos sociais entre o biógrafo e o biografado, tem-se uma documentação privilegiada, por expor a memória social do período com riqueza de dados. Com visão compartilhada a nossa, podemos citar os classicistas J. S. Richardson, Jane Bellemore e Clayton Morris Hall ${ }^{15}$.

Quanto à produção de Nicolau, é fundamental retomarmos o Léxico Bizantino (Suda). Nicolau escreveu uma história universal (80 livros), uma biografia sobre Augusto e uma autobiografia, dessas apenas sobrevivem os fragmentos referentes à biografia augustana e a sua vida (Suda, N' 393). Quanto ao escrito biográfico sobre Augusto, para W. Steidle (1963), a obra foi desenvolvida de forma completa. Em contraposição a Steidle, Arnaldo Momigliano (1993, p. 11-2) frisa que, pelas suas características textuais, Nicolau desenvolveu uma biografia parcial. Momigliano ressalta que Nicolau, por meio dos longos fragmentos sobre Augusto, foi um dos maiores representantes do estilo helenístico de biografia no período romano. Em sua construção, vale-se do modelo peripatético para elaborar sua produção textual. Para Momigliano, o período de construção da biografia augustana, pelo autor de Damasco, foi aproximadamente em 20 AEC, o que denota uma interface com o processo de concentração do poder político de Augusto, assim como o reforço do mos maiorum $^{16}$ e a difusão da cultura latina, no Ocidente Mediterrâneo.

A razão biográfica de Nicolau fica expressa, quando ele indica que vai relatar as realizações de César Augusto, “[...] para que todos possam conhecer a verdade” (FGrH 90 F. 126.2). Para tanto, Nicolau argumenta que vai estruturar seu escrito biográfico primeiro falando do nascimento e da criação pelos pais de Augusto. Assim como destacou, a "[...] disciplina e educação desde a infância, por meio da qual ele veio a ter tal posição social" ( $F G r H 90$ F. 126.2). A obra detém um conjunto de elementos chaves para a construção das virtudes augustanas.

\section{Os escritos biográficos de Suetônio sobre Augusto como exemplum}

Nesse contexto de escritos biográficos, a produção literária de Caio Suetônio Tranquilo (século II EC) intitulada de Vida dos Doze Césares (De Vita Caesarum) instiga-nos por seus minuciosos detalhes sobre a trajetória dos imperadores. Philip Stadter (2007, p. 528-540) argumenta que Suetônio se valeu da Biografia Histórica, por esse gênero literário melhor narrar aos acontecimentos do sistema do Principado, como vemos nos próprios escritos sobre Augusto. Assim, indagamo-nos 
sobre algumas seleções de Suetônio, como: Quais as características que podemos evidenciar da obra Vida do Divino Augusto, de Suetônio? Quais as suas possíveis intencionalidades do autor? Quais as construções efetuadas pelo biógrafo para elaborar uma imago principis que fosse divinizada?

Para Antonio R. de Verguer, comentador da referida obra, tal produção é constituída de oito livros completos. Verguer frisa que os livros seguem a respectiva organização: I - Júlio César; II Augusto; III - Tibério; IV - Calígula; V - Claudio; VI - Nero; VII - Galba, Otão, Vitélio; VIII - Vespasiano, Tito e Domiciano. O texto possui como objetivo central a descrição de informaçóes relativas ao âmbito público e privado dos personagens. Sendo assim, em Suetônio encontramos temas frequentes como: a matriz familiar e os seus ancestrais, a forma e o local do nascimento, $\mathrm{o}$ qual era acompanhado por inúmeras qualidades de presságios sobre o sucesso do sujeito, a infância, o começo de sua vida pública, além de aspectos relevantes do governo, as construçóes e os jogos efetuados, as relaçóes familiares e questóes de vida privada, o contexto da morte. Segundo Verguer ${ }^{17}$, há um consenso histórico em se aceitar como possibilidade de publicação dos livros os anos de 119 a 120, momento do governo do princeps Adriano (117 - 138).

Um ponto a ser ressaltado sobre Suetônio, é que o autor não emprega a mesma forma de escrita biográfica em todos os seus livros. Assim, as produçôes variam em estilo e forma de acordo com as suas preferências e intencionalidades para composição, como foi pontuado por Antonio R. de Verguer (1992, p. 20-4). Cotejando os apontamentos de Verguer com José L. Brandão, evidenciamos que os livros de Suetônio têm atributos laudatórios ${ }^{18}$, por exemplo, no que tange às descrições referentes à Vida de Germânico; no começo da Vida de Calígula; na parte inicial da Vida de Cláudio; bem como a maneira de iniciar a Vida de Tito. Para Brandão, outro elemento constituinte desse mosaico de estilos e formas de escrita biográfica foi a concepção de felicitas $^{19}{ }^{1}$ como um atributo que, desde o início, manifesta-se nas vidas dos bons imperadores - como Augusto, Vespasiano ou Tito - e a de infelicitas ${ }^{20}$ nos que ele considera como maus governantes - Nero. Essa perspectiva de Suetônio materializa-se quando observamos os seus apontamentos sobre como os deuses abençoaram os bons com uma "boa morte" e puniram os maus com uma morte descrita como terrível e solitária.

Ademais, ao confrontarmos os estudos produzidos por Antonio R. de Verguer (1992, p. 20-24), Catharine Edwards (2008, p. VII-XXX) e José L. Brandão (2009, p. 15-28), verificamos que estes convergem ao indicar que a principal intencionalidade de Suetônio era a elaboração de um modelo de optimus princeps, em muitos casos tomando como exemplo o Panegírico de Trajano - de Plínio o Jovem - e as Res Gestae - de Augusto. Vale ressaltar que, para Suetônio, o princeps ideal era Augusto, cuja biografia é a mais completa e extensa dentre as que foram produzidas por ele. É importante frisar que a construção discursiva da imago principis augustana foi consolidada e apropriada por várias gerações de escritos latinos e gregos, desde a sua morte em 14 EC.

Ao frisarmos que os biógrafos tomavam Augusto como um exemplum, evidenciamos que havia um interesse em criar um modelo de comportamento, o qual deveria ser emulado pelos seus sucessores. Logo, pensamos na terminologia latina aemulatio para refletir a elaboração de uma imago principis augustana que foi representada pela documentação abordada agora. Ao interagirmos com o Oxford Latin Dictionary (GLARE, 1968-1982, p. 64), The Oxford Classical Dictionary (HORBLOWER; SPAWFORTH, 1996), A Latin Dictionary (LEWIS; SHORT, 1958, p. 55), pontuamos que a aemulatio pode ser entendida como uma emulação, bem como um esforço de forma contínua, cuja finalidade seria igualar um sujeito com outro ser ou alguma coisa. Com isso, 
à medida que Suetônio argumenta sobre as características do governo augustano e a sua personalidade virtuosa, com uma evidente euforização, esse escrito promove uma nítida emulação a partir da qual os principes contemporâneos e posteriores deveriam se igualar.

Nathália Frazão José (2011, p. 64-67) ressalta que a construção suetoniana de uma "imagem augustana”, como o defensor de Roma, ratificava o sistema político do Principado Romano, no qual o princeps Adriano era o governante e um dos patronos ${ }^{21}$. Mediante leituras sobre Georges Balandier (1982, p. 64-65), notamos que, por meio da literatura, é possível efetuar jogos políticos sobre figuras de destaque, em muitos casos, com a intencionalidade de edificar e consolidar os mais diversos regimes ao longo da história. Em nosso caso, o que percebemos historicamente é a formulação de uma densa rede discursiva, a qual se torna ao mesmo tempo sutil e poderosa, por promover um conjunto de interconexóes entre o "passado de Augusto" e o "presente de Adriano" (CIZEK, 1977, p. 121-124; 181-189). Catherine Edwards (2008, p. XIX-XX) ressalta que a forma e estilo de escrita de Suetônio apenas obteve êxito devido ao contexto histórico favorável às atividades literárias em prol da dinastia antonina. Assim, o autor clássico no começo de seus escritos da Vida do Divino Augusto, revela-nos o modo como operacionalizou este livro: "Exposto essa espécie de resumo de sua vida, tratarei de suas partes isoladas e não cronologicamente, por itens, para que possam ser mais distintamente enunciadas e conhecidas" (Vida do Divino Augusto, 9). Com esse intuito, Suetônio demonstra o seu objetivo de fazer conhecer os mais diversos aspectos que integraram a vida de Augusto.

Contudo, aqui nos interessa analisar como Suetônio construiu a figura de Augusto, especificamente. Assim, convergimos com Raoul Girardet, por esse último destacar que um mito político é composto de homens, os quais se encontravam inseridos em certo espaço geográfico e em certa fase do tempo. Para Girardet, tais homens perpassaram por construçóes discursivas sobre a sua trajetória política, em muitos casos lhes conferindo vinculações com a esfera do sagrado. Quanto mais um mito politico ganha amplitude, "[...] mais ele se estende por um largo espaço cronológico e se prolonga na memória coletiva, mais se deve esperar, aliás, ver os detalhes biográficos, as características físicas ganhar importância” (GIRARDET, 1987, p. 81-82). Afinal, os discursos com conotaçóes míticas são portadores de diversos significados, como Roland Barthes (2007, p. 219) ressaltava em seus escritos. Ponto esse que se torna pertinente para a análise sobre as representações de Otávio Augusto.

Mediantes as nossas leituras sobre Barthes, notamos que os mitos politicos são reveladores do contexto social em que são produzidos. Tendo em vista que estes discursos atuam como mensagens formuladas por meio de uma linguagem, sendo esta dotada de intencionalidade e intrinsecamente relacionada a um sujeito ou grupo social. Nessa perspectiva, um discurso está atrelado aos diversos interesses pessoais de tal maneira que a ação discursiva não deve ser pensada de forma simplista, em razão da mensagem contida em seu conteúdo (GREIMAS; COURTÉS, 1979, p. 125-130). Precisamente, essa visão pode ser materializada em Suetônio, pois é possível notarmos características de Augusto que são reforçadas por intermédio dos mais singelos gestos, assim como expressóes corporais que são evidenciadas para exaltar sua imagem e construí-la como algo poderoso.

Nos escritos suetonianos, vemos, por exemplo, as descrições de atributos políticos que eram vitais para Roma. Destacamos, sobretudo, o ponto da virilidade romana - por ser um quesito fundamental em um meio social falocrático. Ademais, podemos acrescentar o fulgor divino em suas expressões, como vemos a seguir: 
Desfrutou de rara beleza e foi bastante atraente ao longo de toda sua vida. Contudo, prescindiu de qualquer adorno e a tal ponto era descuidado com os cabelos que se prestava às pressas e ao mesmo tempo aos cuidados de vários barbeiros, e raspava ou aparava a barba enquanto lia ou mesmo escrevia algo. Tinha as feiçôes tão tranquilas e serenas quando falava ou se calava, que um dos nobres gauleses declarou aos companheiros ter sido de tal modo inibido e abalado por sua presença que, ao ter-se aproximado dele a pretexto de conversar, não o lançou de um precipício durante a travessia dos Alpes como determinara fazer. Tinha os olhos claros e brilhantes: chegava mesmo a desejar que se julgasse haver neles uma espécie de força divina, e alegrava-se caso, a alguém que o olhasse mais fixamente, fizesse baixar o rosto como que diante do brilho do sol. Mas durante a velhice, enxergou menos com o olho esquerdo. Seus dentes eram espaçados, pequenos e desiguais; os cabelos, levemente anelados e alourados; as sobrancelhas unidas; as orelhas, de tamanho médio; seu nariz, mais saliente no alto e menos embaixo; sua tez era intermediária entre morena e alva; sua estatura, baixa; (Vida do Divino Augusto, 89).

Tomando como base os escritos de Jean-Paul Thuillier (2012, p. 71-124), para evidenciar que o belo homem em Roma não era aquele detentor de expressóes efeminadas. Para o autor, os traços masculinos, o preparo físico e a postura para se expressar eram elementos que integravam a concepção de beleza e de virilidade, as quais eram inerentes ao adulescens ${ }^{22} \mathrm{da}$ aristocracia romana. Tais atributos denotavam também que o jovem estava apto para as investidas no campo da guerra. Marco Túlio Cícero relaciona a beleza com a dignitas ${ }^{23}$ de um cidadão romano: "[...] a dignidade do aspecto físico deve ser salvaguardada pela qualidade da cor e esta cor pelos exercícios do corpo $[\ldots]^{24 ”}$. Logo, pelo preparo físico do corpo e pela coloração da pele refletindo a exposição ao sol em atividades atléticas, os uiri romani eram construídos como modelos de beleza, em detrimento do que era considerado como "não masculino". O efeminado era aquele sujeito de coloração alva, corpo delicado e incapaz para a atividade militar, com a voz fina e sem postura para o exercício da oratória. Suetônio deixa transparecer que Augusto era um modelo de beleza masculina entre os romanos da época por deter todos os elementos inerentes ao uir bonus.

Um ponto que devemos salientar reside nas bases que Suetônio provavelmente se utilizou para a construção de seus discursos sobre o princeps Augusto, tão distante espacialmente dele. De imediato, ressaltamos que o referido biógrafo possuía acesso às fontes para sua pesquisa e escrita, por ele ter sido funcionário da biblioteca imperial e assessor de correspondências de Trajano e Adriano até sua demissão em 121/2 EC. Ainda assim, é um fato que grande parte da Vida de Augusto é feita sem identificaçóes diretas desses documentos, um ponto que para Eugen Cizek (1977, p. 44-48) e David Wardle (2014, p. 18-28) demonstra o próprio peso que os Anais detinham na produção de Suetônio. Contudo, podemos afirmar que ele não se limitou a esse único tipo de fonte de dados. Sendo assim, a partir de uma leitura da fonte percebemos que Suetônio também cita outro conjunto de informações da época do princeps Augusto, as quais também poderiam ser oriundas de histórias orais, escritas, construções e inscrições que eram anteriores a ele.

Tristan Power (2014, p. 1-20) argumenta que entre essas fontes operacionalizadas por Suetônio, as Res Gestae Diui Augusti exerceram uma forte influência em sua forma e estilo de representar os feitos do princeps. Ademais, no caso da literatura latina, David Wardle aponta que a Vida dos Doze Césares revela um fascínio de Suetônio por leituras oriundas do período da República e o começo do Principado de Roma. Alguns desses autores, no que tange à Vida do Divino Augusto, são: Cássio de Parma (4), Aquílio Níger (11), Júlio Saturnino (17), Valério Messala (74), Cornélio Nepos (77), 
Júlio Maratos (79; 94), Asclepíades de Mendes (94) e C. Druso (94), bem como uma menção de Cremúcio Cordo (35). Cabe ressaltar também que, no campo da produção literária escrita e da cultura material, há um grande problema para localizar alguns desses materiais, levando em conta que muitos deles não sobreviveram ao tempo e, com isso, gerando dificuldades para confrontar certas informações.

Dos autores que Suetônio mobilizou em sua obra, dois deles nos chamam a atenção pela descrição que fazem de prodígios e manifestações do plano sagrado em relação a Augusto. São eles Asclepíades de Mendes e Júlio Maratos, a respeito dos quais não temos muitas evidências históricas. No caso de Asclepíades, sabemos que este foi autor das Theologoumena, que são considerados

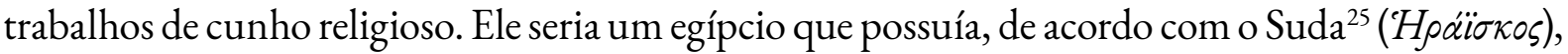
um profundo conhecimento da teologia egípcia e escreveu hinos aos seus deuses nativos. De acordo com William Smith e David Wardle ${ }^{26}$, parece haver pouca dúvida de que este Asclepíades é o mesmo citado em Suetônio (Suet. Aug. 94). Outra convergência entre Smith e Wardle é a de que Asclepíades seja contemporâneo de Augusto assim relatando algumas questóes que envolviam a gestação do princeps. Indicamos que Suetônio pode chamar Asclepíades de Mendes como referência à cidade de origem do escritor no Egito.

Segundo o historiador Christopher Smith (2013, p. 484), Júlio Maratos foi um liberto da Domus Augusta. Além disso, ele mantinha possíveis contatos com Augusto, pois seria assistente do próprio princeps, como podemos observar em estudos de fragmentos contidos no livro The Fragments of the Roman Historians (2013). Podemos tecer uma suposição de que Júlio Maratos foi um uerna, ou seja, um escravo criado na casa imperial, bem como possuía uma inserção com a família do princeps. Na perspectiva de Smith, os escritos de Maratos foram elaborados em período posterior à morte de Augusto, como uma forma de preservação da memória, assim retratando o nascimento e a aparência do seu antigo senhor.

Em linhas gerais, a obra de Nicolau de Damasco fornece-nos indícios históricos, os quais, em consonância com outros documentos literários, auxiliam-nos a preencher lacunas sobre o contexto social em que Otávio Augusto estava inserido. Por isso, a biografia de Nicolau torna-se uma chave vital para esse processo de construção histórica. Percebemos também que Suetônio fundamentou suas concepçôes na maior parte de relatos possíveis para a construção da biografia de Otávio Augusto. Entre esses antigos autores clássicos, Julio Marato e Asclepíades de Mendes foram fundamentais para a construção do nascimento divino de Augusto.

Logo, a compreensão da "linguagem" de cada tipo de documento é vital para entendermos o sujeito locutor e os enunciados ali presentes. Dessa maneira, uma análise contextual-histórica em conjunto com o gênero literário da documentação nos possibilita lidar com as especificidades de seu discurso, bem como nos fornece acesso aos vestígios que, em uma primeira leitura, não são evidentes. Ao cotejarmos tais análises, torna-se possível perceber vozes e figuras que, em primeira leitura, passam desapercebidas, mas que possuem relevância para uma época, seja para endossar o poder de Otávio Augusto, questioná-lo ou para endossar os relatos dos autores. 


\section{Referências}

ALBRECHT, Michael von. A History of Roman Literature. London: E. J. Brill, 1997. v. 1.

ALFOLDY, Géza. A História Social de Roma. Lisboa: Editora Presença, 1989.

ASSMANN, Jan. Para Além da Voz, Para Além do Mito. Revista Humboldt, ano 45, 2003. p. 5-9.

ASSUMPÇÃO, Luis Filipe Bantim de. Antigas críticas e novas perspectivas sobre a biografia: um estudo de caso sobre Xenofonte (V a.C.). In: NETO, José Maria Gomes. Antigas Leituras: olhares do presente ao passado. Rio de Janeiro: Autografia, 2016. p. 278-292.

BALANDIER, Georges. O poder em cena. Brasília, DF: Ed. UnB, 1982.

BARTHES, Roland. Mitologias. Rio de Janeiro: Difel, 2007.

BOWERSOCK, G. R. Suetonius and Trajan: Hommages a Marcel Renard. Bruxelas: J. Bibauw, 1969. p. 119-125. (Collection Latomus, 101).

BRADLEY, K. R. The Composition of Suetonius' Caesares again. Journal Indo-European Studies, v. 1, p. 257263, 1973.

BRANDÃO, José Luis Lopes. Suetônio e os Césares. Teatro e Moralidade. Coimbra: Ed. CECH, 2009.

BUSTAMANTE, Regina M. da Cunha. Práticas Culturais no Império Romano: Entre Unidade e a Diversidade. In: SILVA, Gilvan Ventura da; MENDES, Norma Musco (org.). Repensando o Império Romano: Perspectiva Socioeconômica, Política e Cultural. Rio de Janeiro: Mauad; Vitória, ES: EDUFES, 2006. p. 109-133.

CAMPOS, Carlos Eduardo da Costa. O forum romanum e a formação social do vir bonus: o caso de Caio Otávio. Romanitas: Revista de Estudos Grecolatinos, n. 4, p. 138-155, 2014.

CIZEK, Eugen. Structures et idéologie dans: les vie des douze Césars de Suétone. Paris: Les Belles Lettres, 1977.

DE VERGUER, Antonio Ramirez. Introduction. In: SUETONIO. Vida de los Doce Cesares. Tradução Rosa Maria Cubas. Madrid: Editorial Gredos, 1992. p. 20-24.

EDWARDS, Catherine. Introduction. In: SUETONIUS. Lives of the Caesars. Oxford: Oxford University Press, 2008. p. VII-XXX.

ESTEVES, Anderson Araújo Martins. Os textos literários antigos e o historiador: desafios e abordagens. Cadernos do LEPAARQ, v. XII, n. 24, 2015, p. 200-210.

FUHRMMAN, Manfred. La Literatura Romana. Madrid: Editorial Gredos, 1985.

GIRARDET, Raoul. Mitos e mitologias políticas. São Paulo: Companhia das Letras, 1987.

GLARE, P. G. W. Oxford Latin Dictionary. Oxford: Claredon Press, 1968-1982.

GREIMAS, Algirdas Julien; COURTÉS, Joseph. Dicionário de Semiótica. São Paulo: Ed. Cultrix, 1979.

JOSÉ, Natália Frazão. A construção da imagem do imperador Augusto nas obras de Veléio Patérculo, Plutarco e Suetônio. Dissertação (Mestrado em História) - Faculdade de Ciências Humanas e Sociais, Universidade Estadual Paulista Júlio de Mesquita Filho, Franca, 2011. p. 64-67.

HALL, Clayton Morris. Preface. In: Nicolaus of Damascus' life of Augustus: a historical commentary embodying a translation. Tradução Clayton Morris Hall. Massachusetts: Kessinger Legacy Reprints, 1923. p. 1-2.

HAMILTON, Nigel. Biography, a brief history. Harvard: University Press, 2007.

HAZEL, John. Who's who in the Roman World. London; New York: Routledge, 2001.

HORBLOWER, Simon; SPAWFORTH, Antony. The Oxford Classical Dictionary. Oxford: Oxford University Press, 1996.

KASHER, Aryeh. King Herod: a persecuted perscutor - a case study in psychohistory and psychobiography. Berlin: Walter de Gruyter GmbH \& Co. KG, 2007. 
LEWIS, Charlton T.; SHORT, Charles. A Latin Dictionary. Oxford: Clarendon Press, 1958.

MADELÉNAT, Daniel. La biographie. Paris: PUF (Littératures modernes), 1984.

MARINCOLA, John. Introduction. In: MARINCOLA, John. A Companion to Greek and Roman Historiography. Oxford, UK: Blackwell Publishing Ltd, 2007. v. 1, p. 1-10.

MARTIN, René; GAILLARD, Jacques. Les genres littéraires à Rome. Paris: Nathan, 1990.

MOMIGLIANO, Arnaldo. The Development of Greek Biography. London: Harvard University Press, 1993.

MOMIGLIANO, Arnaldo. As Raízes Clássicas da Historiografia Moderna. Bauru: EDUSC, 2004, p. 12-14.

NICOLAU OF DAMASCUS. Nicolaus of Damascus' life of Augustus: a historical commentary embodying a translation. Tradução Clayton Morris Hall. Massachusetts: Kessinger Legacy Reprints, 1923.

PEREIRA, Maria Helena da Rocha. Estudos da História da Cultura Clássica. Volume Il: Cultura Romana. Lisboa: Fundação Calouste Gulbenkian, 2009.

PEREIRA, Susana Marques. Motivos clássicos na poesia novilatina em Portugal: Manuel da Costa. In: SILVA, Maria de Fátima Sousa; AUGUSTO, Maria das Graças de Moraes. A recepção dos clássicos em Portugal e no Brasil. Coimbra: Imprensa da Universidade de Coimbra, 2015. p. 161-172.

PLUTARCH. Plutarch's Lives. Tradução Bernadotte Perrin. London: William Heinemann Ltd., 1919. v. 7.

POLLAK, Michael. Memória, esquecimento, silêncio. Estudos Históricos. Rio de Janeiro: Fundação Getúlio Vargas, v. 2, n. 3, p. 3-15, 1989.

POLLAK, Michael. Memória e identidade social. Estudos Históricos. Rio de Janeiro: Fundação Getúlio Vargas, v. 5, n. 10, p. 200-212, 1992.

POWER, Tristan. Introduction: Originality of Suetonius. In: POWER, Tristan; GIBSON, Roy. Suetonius the biographer. Oxford, UK: Oxford University Press, 2014. p. 1-20.

RAWSON, Beryl. Children and Childhood in Roman Italy. Oxford, UK: Oxford University Press, 2003. p. 255-256.

SAMARA, Eni Mesquita. A Historiografia recente e a pesquisa multidisciplinar. Revista Phoînix. Rio de Janeiro, n. 11, p. 9-28, 2006.

SARAIVA, Francisco Rodrigues dos Santos. Dicionário Latino-Português: Etimológico, Prosódico, Histórico, Geográfico, Mitológico, Biográfico etc. Rio de Janeiro: Livraria Garnier, 2006.

SCHMIDT, Benito Bisso. História e Biografia. In: CARDOSO, Ciro Flamarion; VAINFAS, Ronaldo (org.). Novos Domínios da História. Rio de Janeiro: Elsevier Editora, 2012. p. 187-205.

SMITH, Christopher. 65: Julius Marathus. In: CORNELL, Timothy J. The Fragments of the Roman Historians. Oxford, UK: Oxford University Press, 2013. v. 1, p. 484.

STADTER, Philip. Biography and History. In: MARINCOLA, John. A Companion to Greek and Roman Historiography. Oxford, UK: Blackwell Publishing Ltd, 2007. p. 528-540.

SUETONIO. Vida de los Doce Cesares. Tradução Rosa Maria Cubas. Madrid: Editorial Gredos, 1992.

SUETONIO. Vida do Divino Augusto. Tradução Matheus Trevizam, Paulo Sérgio Vasconcellos, Antônio Martinez Rezende. Belo Horizonte: Ed. UFMG, 2007.

SUETONIO. Lives of the Caesars. Tradução Catherine Edwards. Oxford: Oxford University Press, 2008.

THUILLIER, Jean-Paul. Virilidades romanas: vir, virilitas, virtus. In: VIGARELLO, Georges. História da Virilidade: a invenção da virilidade da Antiguidade às Luzes. Rio de Janeiro: Ed. Vozes, 2012. p. 71-124.

WARDLE, David. Introduction. In: SUETONIUS. Life of Augustus: Vita Divi Augusti. Tradução David Wardle. Oxford, UK: Oxford University Press, 2014. p. 18-28.

WHITMARSH, Tim. Ancient History Through Ancient Literature. In: ERSKINE, Andrew. A companion to Ancient History. Oxford: Blackwell Publishing, 2009. p. 77-86. 


\section{Notas}

1. Para Michael Pollak (1989, p. 3-15; 1992, p. 200-212), a memória é ao mesmo tempo individual, do ponto de vista pessoal, e coletiva, todo ponto de vista do grupo, definindo o que é comum a esse grupo e o que o diferencia de outros. Essa memória é o que permite fundamentar e reforçar os sentimentos de pertencimento e as fronteiras socioculturais. A memória deve ser entendida também, sobretudo, como um fenômeno coletivo e social, construída a partir de um fenômeno coletivo, submetido a flutuações, transformações e mudanças constantes.

2. Segundo Cícero, “[...] assim Catão, um escritor da mais alta autoridade, diz em suas Origens, que ‘Foi nossos antepassados que instituíram o costume de entreter aos convidados, assim celebrando os louvores e virtudes dos homens ilustres por meio de canções ao som da flauta'; são poemas claros e musicais que foram então compostos para a voz. E, de fato, está claro assim que a poesia estava dentro das Leis das Doze Tábuas, em medida que nenhuma canção poder ser feita para causar prejuízo aos outros comentários" (Tusculana IV, 2).

3. Harriet I. Flower, na obra Roman Republic (2010); Karl Galinsky, em The Cambridge Companion to the age of Augustus (2005); David Shotter, The fall of the Roman Republic (1994); Liv M. Yarrow, Historiography at the End of the Republic Provincial Perspectives on Roman Rule (2006).

4. Novo sistema político de governo engendrado por Augusto, no qual ele enquanto princeps (primeiro entre os cidadãos) detinha o poder de comando da sociedade romana, mediante a elaboração de uma ampla rede de colaborações sociopolíticas, assim como de discursos e representações.

5. As representações são construções elaboradas acerca de um sujeito, um grupo e/ou um objeto no intuito de interpretar/ explicar as práticas desempenhadas em um meio social. Todavia, as representações desenvolvidas em uma sociedade não são neutras e correspondem aos interesses dos grupos que as elaboraram (GREIMAS; COURTÉS, 1979, p. 382-383).

6. Concepção formulada a partir de Daniel Madelénat, em La biographie (1984, p. 32-41); Arnaldo Momigliano, em As Raízes Clássicas da Historiografia Moderna (2004, p. 12-14); Benito Bisso Schmidt, em História e Biografia (2012, p. 195); Philip Stadter, em Biography and History (2007, p. 528-540).

7. A partir de Algirdas Julien Greimas e Joseph Courtés, o ato de euforizar consiste na valoração positiva de um sujeito ou objeto de interesse, por meio da exaltação no âmbito discursivo (GREIMAS; COURTÉS, 1979, p. 170).

8. Algirdas Greimas e Joseph Courtés esclareceram que o ato de disforizar reside na valorização de um microuniverso semântico, cujo propósito seria desqualificar práticas políticas, culturais e sociais de um dado grupo de sujeitos (Ibidem, p.130).

9. Concepção fundamentada a partir de Jan Assmann, em Para Além da Voz, Para Além do Mito (2003, p. 5-9) e Michael Pollak, em Memória, esquecimento, silêncio (1989, p. 3-15).

10. Nossa visão aproxima-se de Luis Filipe Bantim de Assumpção, ao tomar este escrito plutarquiano como base de suas análises sobre a biografia antiga, conjectura que no Mundo Antigo: “[...] a biografia traçava a trajetória de vida de homens proeminentes, no intuito de enfatizar os seus feitos político-militares e estabelecer modelos de conduta moral e social" (ASSUMPÇÃO, 2016, p. 278-292).

11. Em muitos casos, esses modelos de comportamentos políticos permearam as gerações posteriores, assim atravessando séculos. Para Susana Marques Pereira, é possível notarmos na sociedade portuguesa do século XVI um uso de elementos do exemplar romano, para comparar os feitos e ações da aristocracia. A autora ressalta que Manuel da Costa, um famoso jurista e poeta português do Renascimento, foi responsável por produzir dois epitalâmios de tema nacional em latim sobre o teor acima exposto. Para a autora, o tom de escrita de Manuel da Costa era encomiástico. Com isso, o referido poeta cantou as núpcias do infante D. Duarte com D. Isabel de Bragança, em 1552. De modo semelhante, um ano depois, o matrimônio do príncipe João, herdeiro de D. João III, com a princesa Joana de Castela. Nesse contexto, uma retomada de elementos clássicos foi produzida. Segundo Pereira, havia uma euforização da proeminente família real da noiva, na ilustre figura do imperador Carlos V, seu pai. Logo, uma narrativa de suas conquistas e façanhas foi produzida para exaltar sua imagem real. Para a autora, tais feitos do soberano de Castela são laudatoriamente comparados a um exemplum da história de Roma, ou seja, o ordenador social e estabelecedor das fronteiras do princeps Augusto, com o qual o monarca Carlos V é identificado. Um modelo de conduta e ação, com a qual os novos governantes deveriam ter como base (PEREIRA, 2015, p. 161-172).

12. Para saber mais detalhes, sugere-se consultar Fócio, Biblioteca, 189 ou Ateneu de Naucratis, Deipnosofistas, XIV, 652. Disponíveis em: <http://attalus.org/translate/nicolaus2.html>. Acesso em: 20 jul. 2014.

13. Herodes já se encontrava como aliado romano desde Júlio César, que o concedeu a cidadania romana em 47 AEC. Sua função política na dinâmica dos segmentos dirigentes de Roma veio a permanecer até o período de governo de Augusto (KASHER, 2007, p. 3, p. 19-20). 
14. O termo domus aplica-se não somente para a casa, propriamente dita, como se amplia para designar a família que ali habita (LEWIS, 1958, p. 609-610).

15. Vide Jane Bellemore, em Nicolaus of Damascus - Life of Augustus (1984); Clayton Morris Hall, em Nicolaus of Damascus' life of Augustus - A historical commentary embodying a translation (1923); J. S. Richardson Augustan Rome - 44 BC. to $A D 14$ (2012).

16. O mos maiorum pode ser compreendido como o conjunto de costumes e valores tradicionais, passados pelos ancestrais, que devem ser mantidos para a manutenção da estabilidade social e identificação do ser romano (BUSTAMANTE, 2006, p. 112).

17. O tema tornou-se polêmico entre os anos 60 e 70, do século XX, no que tange ao período de produção da obra. G. W. Bowersock, sustentava que as seis últimas biografias (Galba - Domiciano) foram efetuadas durante o governo de Trajano. Tal hipótese foi refutada, posteriormente, por especialistas como K. R. Bradley, por intermédio de amplos estudos literários e linguísticos (BOWERSOCK, 1969, p. 119-125; BRADLEY, 1973, p. 257-263; DE VERGUER, 1992, p. 20-24).

18. A historiografia aponta-nos que nos rituais fúnebres dos magistrados e demais membros proeminentes de sua família em Roma, um orador era convocado para proferir um discurso, no qual as glórias e honras do morto deveriam ser exaltadas e comparadas com as que seus antepassados realizaram (BRANDÃO, 2009, p. 21; HAMILTON, 2007, p. 11; MADELÉNAT, 1984, p. 39).

19. Felicidade, prosperidade, ventura que são concedidas pelos deuses à vida dos homens por eles agraciados (SARAIVA, 2006, p. 478).

20. Infortúnio, desgraça, infelicidade que são fornecidas pelas divindades para os sujeitos que rompem com a pax deorum, por possuírem ações consideradas como ruins e que se configuram como ímpios (Ibidem, p. 602).

21. Protetor ou defensor de outro cidadão (SARAIVA, 2006, p. 854).

22. Fase que iniciava após o ritual do tirocinium fori (entre os 14 e 17 anos), um novo estágio iniciava-se para o agora cidadão, a adulescentia romana, que se estendia até os vinte e sete anos. Esse estágio é vital não somente para o aprendizado da retórica e da oratória, mas também para execução dos discursos pelos rapazes que integravam a aristocracia romana. Logo, um cidadão ativo necessitava expressar-se e portar-se de forma marcante na vida pública, pois Ihe caberia, no futuro, a ocupação, no cursus honorum, das altas magistraturas, culminando com a obtenção do acesso ao Senado (CAMPOS, 2014, p. 138-155).

23. Segundo Maria Helena da Rocha Pereira, a dignitas se aproxima da noção romana de honor. Tendo em vista que as duas concepções morais romanas se vinculam ao cenário político público. Ao relacionar a perspectiva de Pereira com os escritos de Marco Túlio Cícero, em Cartas aos Amigos (IV,14.1) e Da Invenção (II,166), compreendemos a dignitas como o prestígio político, proeminência e mérito que um cidadão poderia alcançar em autoridade e respeito, no cursus honorum sobre os demais (PEREIRA, 2009, p. 350-381).

24. Vide Marco Túlio Cícero, Dos Deveres, I, 36, 130.

25. Para cotejamento de dados veja a entrada 'Нра́їбкоৎ do Suda Online. Disponível em: <http://stoa.org/sol-bin/search. pl?search_method=QUERY\&login=guest\&enlogin=guest\&page_num=1\&user_list=LIST\&searchstr=heraiskos\&fiel$\mathrm{d}=$ any\&num_per_page=25\&db=REAL>. Acesso em: 24 jan. 2016.

26. Vide maiores informações, no verbete Asclepíades. Disponível em: <http://perseus.tufts.edu/hopper/text?doc=Perseus\%3Atext\%3A1999.04.0104\%3Aalphabetic+letter\%3DA\%3Aentry+group\%3D48\%3Aentry\%3Dasclepiades-bio-7>. Acesso em: 24 jan. 2016.

Data de recebimento: 31/05/2018

Data de aprovação: 20/10/2018 